\title{
Explicit contamination in "implicit" memory for new associations
}

\author{
ELINOR MCKONE and JUDITH A. SLEE \\ Australian National University, Canberra, Australia
}

\begin{abstract}
In one view of implicit memory, priming arises from modification of preexisting representations; however, the role of such representations is currently in doubt following findings of implicit memory for newly formed associations. Closer consideration of studies reporting this effect, and of others that have failed to obtain it, suggests that such priming might result from the employment of explicit memory strategies. With measures designed to permit exclusion of such strategies, three experiments using lexical decision and stem-completion tasks found no evidence of truly implicit memory for unrelated pairs. Instead, priming was found only in those subjects ( $50 \%$ of the total in one experiment) who reported using explicit memory in stem completion. Contrary to previous conclusions, the results indicate a role for established representations in explaining implicit memory.
\end{abstract}

The term implicit memory was introduced by Graf and Schacter (1985) to describe a subconscious use of memory - that is, a facilitation of speed or accuracy of performance in the absence of deliberate reference to a learning episode. This was contrasted with explicit memory, which is revealed in standard recall or recognition tasks and requires conscious recollection of a specific learning event. Implicit memory is usually assessed by tasks in which a target item is "primed" either by an earlier presentation of that target (repetition priming) or by an item similar to it, and performance is compared with that in a baseline condition where the target remains unprimed. Tasks commonly used to measure priming include (1) lexical decision, in which the subject must distinguish between real and nonsense words, (2) identification of a briefly seen or degraded target, (3) stem completion, where the first few letters of a target are presented and the subject is directed to complete the stem with the first word that comes to mind, and (4) fragment completion, in which letters from throughout the target (rather than the stem) are presented for completion.

The delineation of implicit memory was originally inspired by findings that amnesics can exhibit normal priming effects for a list of words while showing very poor recognition or recall of the same list or even failing to recollect that a list had been learned at all (e.g., Jacoby \& Witherspoon, 1982; Moscovitch, 1982; Warrington \& Weiskrantz, 1968, 1970, 1974). Two characteristics of amnesic priming are of particular significance to the argument to be developed here. The first is that amnesics show priming for any items that have a preexisting representation in memory, such as single words (e.g., MOTHER) and

The authors wish to thank Eyal Reingold for valuable comments on an earlier version of this manuscript. Correspondence should be addressed to E. McKone, Division of Psychology, Australian National University, Canberra, ACT 0200, Australia (e-mail: elinor.mckone@anu. edu.au). familiar old associations (e.g., MOTHER-FATHER; see Graf \& Schacter, 1985). The second is that "dense" amnesics (those with little or no residual explicit memory ability) show no priming of items without well-established representations, such as nonwords (e.g., MOTHEN; see Cermak, 1984) or experimentally created new associations (e.g., MOTHER-CALENDAR; see Musen \& Squire, 1993; Schacter \& Graf, 1986b; Shimamura \& Squire, 1989).

These findings are consistent with what Bowers (1994) calls a modification theory of implicit memory. Here, priming arises through the modification of well-established, preexisting memory representations, rather than via a novel trace of the stimulus acquired during the experiment. Most modification theories of implicit memory have assumed that it is leftover activation of a target's internal representation that supports priming (e.g., Graf \& Mandler, 1984; Mandler, 1980; Morton, 1969, 1979), although other forms of modification are theoretically possible (e.g., Burt \& Humphreys, 1993).

All modification theories predict that implicit memory should occur only for stimuli that contact preexisting representations. Thus, the amnesic findings of priming for real words and old associations, but not nonwords and new associations, are consistent with this view. In normals, however, priming of both nonwords (e.g., Bowers, 1994; Dorfman, 1994; Salasoo, Shiffrin, \& Feustel, 1985) and new associations (e.g., Graf \& Schacter, 1985; McKoon \& Ratcliff, 1979) has commonly been observed.

The finding that normals can demonstrate priming for nonwords, while in contradiction to the data from amnesics, is not necessarily in conflict with modification theories. Detailed arguments for this conclusion can be found in Bowers (1994) and Dorfman (1994). Briefly, the point made by these authors is that the word-like nonwords used in most experiments (i.e., pseudowords, such as TRIN or SUBVADE) often share many letter groupings with real words, suggesting that nonword priming may arise through modification of familiar sublexical representations. 
The theoretical implications of priming for new associations in normals cannot be dismissed so easily. For a completely unrelated pair of words, there can be no suggestion of access to any form of well-established representation linking the words as a pair; for this reason, findings of implicit memory for new associations have been instrumental in the decline of modification approaches to priming.

The best known studies demonstrating priming for new associations are those by Graf and Schacter (1985, 1987; Schacter \& Graf, 1986a, 1989). Their subjects performed a variant of the stem-completion task, in which they processed pairs of normatively unrelated words (e.g., MOTHER-CALENDAR) at study. After performing distractor tasks, they were later presented with, say, the stem $\mathrm{CAL} \ldots$, preceded by another word, and were required to complete it with the first word that came to mind. In a same condition, the stem was paired with the study list associate of CALENDAR (i.e., MOTHER-CAL__ ). In a second, different condition, CAL__ was preceded by another word - generally, one that had appeared at study with a different partner. Priming for new associations was demonstrated by higher completion rates with study list targets in the same condition than in the different condition.

Other studies reporting priming for new associations in normals have been conducted by McKoon and Ratcliff $(1979,1986)$, using reaction times rather than targetcompletion rates to assess priming. They showed subjects pairs of new associations at study; at test, they presented the members of a pair successively, requiring a lexical decision response to the second. Lexical decision time to a target word was found to be faster when it was preceded by its original partner than when it was preceded by a different word from the study list.

\section{Explicit Contamination in "Implicit" Tests}

While it is clear that priming for new associations can be readily observed, the question addressed in this article is, How much of such priming genuinely reflects implicit memory? The definition of implicit memory introduced by Graf and Schacter (1985) is made in terms of the subconscious nature of the retrieval process--that is, the subject's experience and behavior at test. However, early work on implicit memory made little attempt to control or evaluate actual retrieval strategies, but instead operationalized implicit memory on the basis of no direct reference to the study phase at test. With indirect instructions (Johnson \& Hasher, 1987) to respond with the "first word that comes to mind," it is possible that normal subjects deliberately retrieved items from the study phase, despite the lack of direct instructions to recall from the original list.

The possibility of explicit contamination on tests designed to tap implicit memory has now received substantial discussion in the literature (e.g., Jacoby, 1991; Johnson \& Hasher, 1987; Richardson-Klavehn \& Bjork, 1988; Roediger \& McDermott, 1993; Schacter, 1985; Schac- ter, Bowers, \& Booker, 1989; Toth, Reingold, \& Jacoby, 1994). Surprisingly, the acknowledgment of the possibility has not necessarily led researchers to question the theoretical relevance of old findings, with some (most notably, Roediger \& McDermott, 1993) overtly choosing to discount the role of any explicit contamination in the evaluation of "implicit" memory data. We believe that a reexamination of old findings is appropriate where the possibility of explicit contamination existed in the original experiments. This would appear particularly important in situations where (1) the finding is of strong theoretical significance and (2) the data from amnesics are in conflict with those from normals. Priming for new associations is an obvious case in point.

Graf and Schacter have presented two general lines of evidence to suggest that normal subjects do not use explicit strategies in their paired-associates stem-completion paradigm. First, they reported (Schacter \& Graf, 1986a) that performance on the last few trials of a stem-completion test was no better than on the first few-a finding inconsistent with the view that subjects had noticed a relationship between the test stems and the study items at some point during the test and had changed to a recall strategy after this point.

Second, they have reported a number of variables that produce dissociations between stem-completion performance and that in an explicit memory control condition (stem-cued recall). Schacter and $\operatorname{Graf}(1986 a)$ found that increasing level of elaboration (LOE) at study improved recall but not priming of new associations, as long as both levels involved semantic processing of the association between the target pair. Graf and Schacter (1987) found that retroactive and proactive interference affected recall but not priming of new associations. Schacter and Graf (1989) found that changing the modality of presentation from study to test reduced priming but not recall of new associations.

Other results argue against the view that priming for new associations is truly implicit. Considering findings from the stem-completion paradigm first, it is known that, while LOE does not influence priming for new pairs if a semantic study task is used, changes in the level of processing (LOP) at study (e.g., from structural to semantic) have equivalent effects on priming and explicit memory for pairs: Both improve with a deeper LOP (Schacter \& Graf, 1986a). Given that LOP effects are not generally found for single-word priming (in normals or amnesics), this suggests that priming for pairs is more similar to explicit memory than to implicit memory.

A second suggestion of explicit contamination in stemcompletion for pairs comes from Bowers and Schacter (1990), who used a postexperimental questionnaire to investigate whether normal subjects notice the relationship between the study and test lists. They then examined their stem-completion data as a function of subjects' awareness, or otherwise, of the origins of the test stems. The relevant finding was that, while priming for single 
words occurred regardless of a subject's awareness, priming for new associations occurred only in those ("aware") subjects who had noticed that some of the test stems could be completed with study-list items.

A final source of evidence of explicit contamination in the stem-completion task comes from partially amnesic subjects: Dense amnesics show no priming for new associations, whereas those with some spared explicit ability do demonstrate the effect (Schacter \& Graf, 1986b; Shimamura \& Squire, 1989). Even more suggestive is Shimamura and Squire's finding that the amount of priming observed for new associations correlates positively with the level of generalized explicit memory ability retained by individual patients.

Turning to the lexical decision studies of McKoon and Ratcliff $(1979,1986)$, we argue that these, too, allow the possibility of explicit contamination in a supposedly "implicit" task. In a standard lexical decision task, where items are presented one at a time in random order, it is assumed, quite reasonably, that the time taken to make a decision "from scratch" (i.e., overtly ignoring any recent presentation of that item) is less than that required to recall the response made to an earlier item (see Hintzman \& Caulton, 1995, for empirical evidence that this is the case). Thus, any deliberate recollection of a previously seen item is unlikely to serve to reduce lexical decision times. McKoon and Ratcliff, however, did not use a standard lexical decision task; their studies presented two items of a pair sequentially, with a relatively long $(>850 \mathrm{msec}$ ) stimulus onset asynchrony (SOA). It has been suggested that, with SOAs of this duration, subjects have time to recognize the first item as a constituent of the study list, to recall its original partner, and, therefore, to predict what the next item will be (Durgunoğlu \& Neely, 1987). This allows faster lexical decision times when the second item is the expected target, producing a priming effect that is at least partly based on explicit, rather than implicit, memory.

With very short SOAs, there would seem to be little chance of contamination by explicit memory strategies; there would be insufficient time for recall of the matching target item to take place, and, under these circumstances, no priming effect for new associations is observed. Studies by Dagenbach, Horst, and Carr (1990), Neely and Durgunoğlu (1985), and Smith, MacLeod, Bain, and Hoppe (1989), all of whom used a $250-\mathrm{msec}$ SOA, and by Carroll and Kirsner (1982), who used simultaneous presentation of the pair members and required lexical decision to both items of a pair at once $(0-\mathrm{msec}$ SOA), have failed to find priming for new associations. Thus, when the likelihood of using explicit strategies is minimized, no priming for new associations is found. This conclusion is strengthened by evidence from Dagenbach et al. that short-SOA priming appears with "new" associates only when these pairs are so overlearned as to have become "old": They found that a 15-min study phase for a list of 24 pairs led to almost perfect cued recall per- formance but did not lead to priming between the associates, and that even a study phase extending over 5 weeks led to priming in only one of the two conditions tried.

\section{Is Priming for New Associations Implicit or Explicit?}

Results of studies using the lexical decision task are consistent with the view that priming for new associations arises only when the possibility of explicit contamination arises through the use of long SOAs. However, a common feature of the short-SOA lexical decision studies may account for their failure to find priming for new pairs. Schacter and Graf (1986a) found that a minimum level of semantic processing at study was required to observe priming for new associations; subjects in the lexical decision experiments mentioned above were not, except in one condition of the Smith et al. (1989) study, required to process items semantically. It could be argued, then, that the failure to find implicit memory for new associations in these studies is attributable to impoverished encoding conditions. Therefore, our Experiment 1 investigated priming for pairs in a short-SOA lexical decision task following a semantic study phase.

Results from the stem-completion paradigm are less consistent, with evidence both for and against the view that priming for new associations genuinely reflects implicit memory. One finding strongly suggestive of explicit contamination is the failure of Bowers and Schacter (1990) to find any priming for new pairs in unaware subjects. Unfortunately, however, Bowers and Schacter did not ask those subjects who "caught on" whether this realization led them to use deliberate recall to complete the test stems. It is possible that, rather than using explicit completion strategies after this realization, aware subjects continued to obey instructions to respond with the first word that came to mind. This interpretation would make their results a true reflection of implicit memory and is consistent with earlier findings that completion rates did not differ between the beginning and the end of the list (although it leaves open the question of why priming for new pairs was not observed in unaware subjects). Given this, our Experiments 2 and 3 investigated priming for new associations with a stem-completion paradigm, using an extended awareness questionnaire in which aware subjects were asked how they treated the task after they became aware.

\section{EXPERIMENT 1}

Experiment 1 used a lexical decision task with simultaneous presentation (Carroll \& Kirsner, 1982) to examine implicit memory for new associations. In order to create conditions favorable to the manifestation of any priming effect, the present experiment incorporated semantic processing at study. Pairs of newly associated words were embedded in sentences. Subjects were required to read each sentence aloud and to rate the degree 
to which pair members "went together." At test, the second member of a study pair was presented simultaneously with, variously, its study-list partner (a same test pair), another word from the study list (a re-pair), or a nonword. (Nonwords were included only to allow a lexical decision response.) Subjects indicated whether or not both members of a test pair were true English words. With this design, implicit memory for new associations would be manifested by faster lexical decision times in the same condition than in the re-pair condition.

To test the power of the design, old associations assumed to have preexisting representations were included (e.g., APPLE-ORANGE). Since priming for familiar paired associates is reliably found, not only with normal subjects but also with amnesics, the present design would be vindicated if this result were reproduced. An additional control was to present subjects with an explicit test of the study pairs following the lexical decision task, in order to ensure that subjects had retained the correct pairings.

As an ancillary issue, the role of semantics in any priming for new associations was investigated. Given the finding that semantic processing is required for the manifestation of such priming, it would seem that a link between the meanings of the words is being primed. This raises the possibility that synonyms of an initial pair member may also become linked to the other member of the pair (Micco \& Masson, 1991); therefore, a third type of test pair was included (a synonym pair), which contained one original member plus a synonym of the other.

\section{Method}

Subjects

Twenty members of the Australian National University (ANU) community, under 40 years of age, volunteered for the experiment. All subjects had English as their first language.

\section{Design}

Type of test pair (same, synonym, or re-pair) and type of association (old vs. new) were both varied within subjects.

\section{Materials}

Study lists. Fifty-six pairs of normatively unrelated words (e.g., LAWYER-STONE) were selected, 14 of which appeared in each of the same and re-pair conditions, and 28 of which were required to prime

Table 1

Two Examples of Unrelated Pairs (Plus Word-Nonword Pairs) From Each of the Same, Re-Pair, and Synonym Conditions at Study and Test in Experiment 1

\begin{tabular}{cccc}
\hline \multicolumn{3}{c}{ at Study and Test in Experiment 1 } & \\
\cline { 1 - 2 } Same & Condition & $\begin{array}{c}\text { Word- } \\
\text { Nonword }\end{array}$ \\
\hline Re-Pair & Synonym &
\end{tabular}

\begin{tabular}{llll} 
LAWYER-STONE & CHURCH-COLONY & AUTHOR-WINDOW & n/a \\
EARTH-STREET & COAST-GARAGE & WRITER-STATUE \\
& COTTAGE-BRANCH \\
& HOUSE-RANSOM \\
Test & \\
LAWYER-STONE COAST-COLONY & WRITER-WINDOW & STATUE-SELLOW \\
EARTH-STREET & CHURCH-GARAGE & HOUSE-BRANCH & PRAVE-RANSOM \\
\hline Note-This construction was repeated for related pairs.
\end{tabular}

Note-This construction was repeated for related pairs. the 14 test pairs in the synonym condition. For the synonym condition, 14 of the 28 study pairs consisted of a cue word and an unrelated target, and the other 14 contained a synonym of the cue word, paired with an extra, nontarget, word. (The second 14 pairs were necessary to ensure that the synonyms, which were later tested in the lexical decision task, had appeared at study.) Table 1 provides examples of all study-test combinations.

This procedure was repeated for 56 pairs of frequently associated words (e.g., BREAD-BUTTER), giving 112 pairs in all. All critical words were highly concrete (Paivio, Yuille, \& Madigan, 1968), and all but 2 were nouns. Each pair was embedded within a sentence and underlined. All sentences were meaningful and formed a reasonable link between the pair.

Test lists. The following construction was carried out separately for the groups of new and old associations. In the same condition, words were paired in the same way as seen at study. In the re-pair test, pairings were mixed within the group of 14 , so that words were paired with an item from the study list that was not their original partner. In the synonym condition, each target was paired with the synonym of its original cue. (Original cues in this condition were not tested.) For each association type, the three test conditions were equated on the average number of letters in each pair and on the total number of syllables in the group of 14 pairs. The old associations averaged 10.3 letters per pair and 40 syllables in total and were generally shorter than the new associations at 12.4 letters per pair and 53 syllables in total.

In addition to the 84 critical test pairs (14 pairs $\times 3$ conditions $\times$ 2 association types), the complete test list contained another 84 words paired with nonwords, so that $50 \%$ of the lexical decision responses would be "no." Nonwords appeared equally often in both cue and target positions. Twenty-eight of the real words in these word-nonword pairs had been seen at study (they were the nontarget words used to prime the synonym condition), to discourage subjects from making lexical decisions simply on the basis of recent familiarity.

Finally, an explicit stem-cued recall test was created. This contained each cue shown at study, paired with the first two letters of its original partner.

\section{Procedure}

All stimuli were presented on an Apple Macintosh computer, using HyperCard to show the study lists and using PsychLab to record reaction times (RTs) in the lexical decision test.

The subjects were tested individually. To start, they were given a 25 -item practice list for the lexical decision task, to familiarize them with the test response. The items of each pair were presented simultaneously, and the subjects were required to decide if both were real English words. If both were words, they responded "yes" via the keyboard with their preferred hand; if, however, a word was paired with a nonword, they responded "no" with the other hand. The interval from response to onset of the next stimulus was $800 \mathrm{msec}$. The subjects were instructed to respond as quickly as possible consistent with making the correct decision.

After the initial practice, the complete experimental list was split into two for a blocked study-test, study-test presentation, since the subjects could not have been expected to learn all 112 pairs at one time. The subjects were then presented with half of the complete study list (i.e., 56 sentences, including half of the total pairs in each condition). The order of presentation of sentences was randomized, with the constraint that synonyms could not appear within 8 sentences of each other. The subjects were required to read aloud each sentence and to rate the degree to which the two underlined words "went together." This ensured that the items had been processed semantically. From the subjects' point of view, it appeared a reasonable task given that some pairs (the old associations) were highly related while others (the new associations) were not. The presentation was self-paced, and the subjects generally spent $5-8$ sec per item. 
This was followed by a brief reminder of the lexical decision task (using an 8-item practice list), and then the test for the first half of the study list. The subjects were warned that they would see some of the items that had been on the study list and that some of these would be paired in the same way whereas some would be differently paired. They were reminded that their task was merely to decide whether the members of each pair were both words. The lexical decision test was presented in two sections, allowing for a short rest break between each.

Finally, the written cued recall test for the first half was presented. The subjects were instructed to read the first word presented and to try to remember its pair from the study list, using the two letters given as a clue.

This procedure, excluding the initial practice, was repeated for the second half of the complete list, with the order of presentation of the two halves counterbalanced across subjects.

\section{Results and Discussion}

Examination of the ratings given to each word pair at study confirmed that the subjects did, indeed, perceive the experimenter-defined old associations as being highly related and the new associations as unrelated: Mean ratings of how well each pair "went together" were 4.8 for old associations and only 1.8 for new associations, where 5 was highly related and 1 was completely unrelated. Given this confirmation, lexical decision times were examined for each type of association; mean RTs for same, synonym, and re-pair conditions are shown in Table 2. RTs were excluded if the response was incorrect, or if the RT was more than 2.5 standard deviations above or below the mean for that subject. Error rates were less than $1 \%$ in all conditions.

To determine whether priming for new and old associations was in evidence, only the same and re-pair conditions were considered. A two-way analysis of variance (ANOVA) ${ }^{1}$ revealed a significant interaction between association type and pair type $\left[F(1,19)=39.4, M S_{\mathrm{e}}=\right.$ $1,268, p<.001]$, indicating that new and old associations should be examined separately. For old associations, same-condition responses were, as expected, significantly faster than responses for the re-pair condition $[t(19)=$ $6.0, p<.001]$, demonstrating implicit memory for wellestablished representations. However, for new associations, no advantage was found for the same condition $[t(19)=0.78, p>.1]$, contrary to what would be expected were implicit memory for new associations present. This

Table 2

Lexical Decision Times (in Milliseconds) and Accuracy of Cued Recall (\% Correct) for Old and New Associations in Experiment 1

\begin{tabular}{lrcrr}
\hline & \multicolumn{3}{c}{ Lexical Decision Time } & \\
\cline { 2 - 3 } & Re-Pair & Synonym & Same & Recall \\
\hline \multirow{4}{*}{ Old Associations } & & \\
$S E M$ & 812 & 823 & 704 & 95.1 \\
& 38 & 44 & 25 & 0.8 \\
$M$ & & New Associations & & \\
$S E M$ & 844 & 836 & 836 & 52.1 \\
\hline
\end{tabular}

occurred despite the fact that the subjects showed reasonable explicit recall of these pairs $(52 \%$ correct in the cued recall task). In addition, there was no correlation $(r=.06)$ between the level of explicit recall exhibited by each subject and the amount of priming (same - re-pair) for that subject, which argues that the lack of priming for new pairs was not attributable to a failure to establish a memory trace at study. ${ }^{2}$

A possible problem with the present experiment is that no overall baseline condition was included - that is, a condition in which lexical decision times were measured to unstudied pairs. Thus, it could be argued that, despite finding significant priming for old associations and reasonably high levels of explicit knowledge of new associations, the experimental manipulation may not have been strong enough to produce any effects of study-phase exposure on RTs to words treated as individual members of (newly associated) pairs. Were this the case, it would be hardly surprising to find no effect of pair type. However, a number of the earlier studies that failed to find priming for new pairs in lexical decision included an unstudied condition and demonstrated priming to individual words in pairs (e.g., Smith et al., 1989, Experiment 1). In addition, a more recent paper using simultaneous presentation and a speeded naming task (Musen \& Squire, 1993) has included this control condition with semantic processing at study: Again, priming for individual words was observed, but there was no priming for new pairs beyond this.

Thus, the present results support those of five separate papers that have failed to find implicit memory for new associations in RT tasks with short SOAs. In particular, they replicate the failure of Smith et al. (1989) to observe the effect even when semantic processing is required at study.

\section{Synonym Condition}

Given that no implicit memory for new associations was observed, the role of word meaning in such an effect cannot be investigated; therefore, no analysis of the synonym condition is presented for new associations. However, such an analysis can usefully be undertaken for old associations (although it requires a digression from our main argument), as a way of investigating whether or not the "link" between a pair of old associates that was primed in the double lexical decision task was a semantic one. Table 2 indicates that there was no transfer of priming to a synonym of the original cue word: RTs to synonym pairs were no faster than those to the baseline re-pairs $(t<1)$. The 14 synonym pairs were then broken down into two types--namely, 7 pairs where the original association seemed clearly semantic (e.g., ORANGE-APPLE), and 7 pairs where the association was, rather, contingent on the members appearing immediately following one another (e.g., FOOTBALL-MATCH). Neither of these subgroups of pairs showed any advantage for synonym pairs over re-pairs (both $t \mathrm{~s}<1$ ). These findings suggest that old associates prime each other through nonsemantic links, pos- 
sibly by accessing a single unitized representation of both pair members (Schacter, 1985; but see McKoon \& Ratcliff, 1992, vs. McNamara, 1992, for debate on the role of unitized representations in priming).

\section{EXPERIMENT 2}

The results of Experiment 1 , in combination with a substantial literature on short-SOA priming effects for pairs, strongly suggest that implicit memory does not occur for new associations with this design. This is consistent with the view that earlier observations of priming with long SOAs were due to subjects' ability to predict the identity of the target in advance, on the basis of explicit recall of the study pairs. However, it could alternatively be argued that implicit memory can occur for new pairs following a single presentation but that whatever traces underlie such memory become available relatively slowly. If this were the case, the effect may become apparent at long, but not short, SOAs. It would also imply that implicit memory for new associations may be seen in a stem-completion task (which does not require speeded responses), despite its absence with the lexical decision task used in Experiment 1.

Experiment 2 used a stem-completion task to assess memory for new associations. Subjects in an explicit condition were given direct recall instructions, whereas those in the indirect condition were given "first word that comes to mind" instructions. Memory for new associations is demonstrated with this task if the target stem is completed with the critical word more often when the stem is paired with the same cue word as seen at study (same condition) than when the cue word did not appear on the study list (new-cue condition). In addition, an overall baseline condition was included, in which a separate set of subjects completed the paired test stems without having been exposed to the study list. For the indirectly instructed subjects, a posttest questionnaire, an extension of that employed by Schacter et al. (1989), was used to investigate any use of explicit strategies.

Two levels of elaboration were used at study (both of which required semantic processing). This manipulation of LOE was included because Schacter and Graf (1986a) dissociated indirect and explicit performance on the basis of LOE and used this dissociation to argue that subjects given indirect instructions were not using deliberate recall. Finally, as in Experiment 1, a synonym test condition was included, where the stem of a study-list pair member was presented with a synonym of its original partner. This was done in order to investigate the role of word meaning in any priming effect observed for new associations.

\section{Method}

\section{Subjects}

Prior to the experiment, 10 volunteer subjects from the ANU community, who were not exposed to the study list, provided a baseline measure of the completion rate of test stems with critical words. For the experiment proper, the subjects were 3 ? ANU students, who received credit toward an introductory psychology course. Ten of these were randomly assigned to the explicit test group. The subjects in the indirect group were sampled until equal numbers were found in two of a number of distinct subgroups that emerged from the awareness questionnaire responses. This required sampling 27 subjects. All subjects were fluent in English, and none had participated in Experiment 1.

\section{Design}

Type of test instructions (indirect vs. explicit) was included as a between-subjects factor. LOE at study (high vs. low) and type of cue given at test (same, synonym, or new cue) were both varied within subjects.

\section{Materials}

Study list. The study list contained 36 critical pairs of new associations (a cue word and a target) chosen from the pairs used in Experiment 1 . Eighteen of these were used at test in the same condition, and 18 were used in the synonym condition, with all 36 also appearing in the unrelated condition. All words were between 3 and 10 letters in length, with target words having at least 5 letters. The 3-letter stem of each target word (e.g., wIN__ was unique in the list, and each was readily capable of completion with at least 10 common words.

Pairs were presented, underlined, in sentences that made rough sense but varied in their meaningfulness. Seven untested filler sentences were included, some to remove primacy and recency effects, and some nonsense sentences to ensure that the rating task (see below) was attempted properly.

Test lists. The same test lists were used for both stem-completion and stem-cued recall; only the instructions differed. Three cue conditions were used, consisting of a cue word paired with the stem of the target. In the same condition, the cue was the target's original studied partner. In the synonym condition, it was a synonym of this cue, which had not appeared at study. In the new-cue condition, a word unrelated to either the target or the original cue was chosen, which had not appeared at study. Table 3 gives examples of study and test pairs appearing in each condition.

For each of the 36 critical pairs in the study list, a given subject saw the test stem paired with the new cue and also with either the same or the synonym cue, giving a total of 72 test items per subject. Two versions of the test list were created to avoid having the same stem appear three times. All stems that appeared in the same condition in one list appeared in the synonym condition in the other, and vice versa. The order of items on the test lists was randomized, and results for the two test lists were combined. The dependent measure was the percentage of stems completed with the targets seen at study.

Awareness questionnaire. A questionnaire (see Table 4) was used after test to determine whether the subjects in the indirect instruction group connected the test with the study phase and to examine their subsequent behavior if they did so. The first four questions were taken from Schacter et al. (1989). If a subject spontaneously mentioned the study episode on the first three questions or answered "yes" to the fourth, he/she was classified as aware. Questions 5 and

Table 3

Two Examples From Each of the Same, New-Cue, and Synonym Conditions in Experiment 2

\begin{tabular}{ccc}
\hline Same & \multicolumn{1}{c}{ New Cue } & Synonym \\
\hline & Study & \\
LAWYER-STONE & CHURCH-COLONY & AUTHOR-WINDOW \\
EARTH-STREET & COAST-GARAGE & COTTAGE-BRANCH \\
& Test & \\
LAWYER-STO_ & ENGINE-COL_ & WRITER-WIN_- \\
EARTH-STR & STUDENT-GAR_ & HOUSE-BRA_-
\end{tabular}


Table 4

\section{Awareness Questionnaire Used in Experiments 2 and 3}

1. What did you think was the purpose of the stem-completion task you just finished?

2 . What was your general strategy in completing the word stems?

3 . Where do you think the words you wrote down came from?

4. While doing the stem-completion test, did you notice whether you completed some of the stems with words studied in the earlier list?

5. How far through the test did you become aware that some of the words were from the study list? (Subjects were asked to point to the test item that had first alerted them to the study-test relationship.)

6. Did this knowledge change the way you treated the task? If it did how did your approach change? Did you still respond with the first word that came to mind?

Note- Questions 1-4 are taken from Schacter, Bowers, and Booker (1989).

6 were added for those subjects who became aware, with the intention of eliciting as much information as possible about how they were treating the task.

\section{Procedure}

The subjects were tested individually. Those in the overall baseline condition were given the test lists with the same instructions given to the indirect group (see below), but without prior exposure to the study list.

For the experiment proper, the study list was presented on an Apple Macintosh using HyperCard, with the presentation time being self-paced (around 5-10 sec per sentence). The subjects were told that they would see a list of underlined word pairs embedded in sentences and that they would later be asked to remember these pairs. The study list was divided into two halves, corresponding to the two LOE conditions, with the halves equalized on word frequency of targets (Kučera \& Francis, 1967). In the low LOE condition, the subjects were simply required to read each sentence aloud and then to rate it on a scale of 1-5 for how meaningfully it related the two underlined words. In the high LOE condition, the subjects were required, in addition, to produce a second sentence or phrase that might logically follow from the first. Three practice trials were given at this task. All subjects completed each LOE condition on one half of the study list, with the order of LOE presentation counterbalanced across subjects.

Two distractor tasks followed, taking about $8 \mathrm{~min}$ in all. The first of these was a list of given names to which the subjects were asked to respond with the first name (given or surname) that came to mind. The second was a list of city names with some letters missing. The task was to complete as many of the cities as possible in 5 min. The distractor tasks were used partly to give the subjects exposure to a format similar to that used in the test and partly to make more convincing the presentation of the test list as just another distractor task to the subjects in the indirect condition.

Next followed the test phase. The subjects in the indirect test group were told to read aloud each context word on the test list and com- plete the target stem with the first word that came to mind. They were told to spend no more than a few seconds on each item and to move on if no word came to mind. At the completion of this task, the awareness questionnaire was administered.

The subjects in the direct test (explicit) group were given lettercued recall instructions, using the same test lists. They were informed that this task was the memory test. They were instructed to read the context word aloud and, if this word made them think of a word that was on the study list that started with the three letters given, to write that word down. They were told that many of the pairs were new, and so they were not expected to complete every word.

\section{Results and Discussion}

\section{Explicit Recall Instructions}

Mean target-completion rates for subjects in all conditions are given in Table 5. For explicit memory, more accurate recall of targets was found when the same cue was used as at study than when a new cue was presented $[t(9)=5.78, p<.001]$, demonstrating that the design produced explicit memory for the newly associated pairs. In addition, the standard LOE effect was found for the same condition, with high LOE, relative to low LOE, leading to better recall $[t(9)=3.7, p<.01]$.

\section{All Indirectly Instructed Subjects}

Comparison with overall baseline. The completion rate of stems with targets for the new-cue condition for all subjects given indirect instructions was $21.6 \%$, significantly above the $12.9 \%$ obtained in the baseline condition in which the subjects were not exposed to the study list $\left(W_{s}=92.5, p<.001\right){ }^{3}$ This demonstrates a priming effect of exposure to individual target words.

Priming for pairs. The more interesting question was whether or not priming was found for the pairings presented at study. Treating all subjects given indirect instructions as a single group did reveal priming for new associations: The target-completion rate in the same condition exceeded that in the unrelated condition $[t(26)=$ $2.06, p<.05]$. Thus, our results replicated those of Graf and Schacter, when their procedure of treating all indirectly instructed subjects as a single group was employed.

\section{Awareness Questionnaire}

Results of the postexperimental awareness questionnaire, however, suggest that the grouping together of all indirectly instructed subjects is inappropriate: Different subjects reported using different strategies in the task. No

Table 5

Percentage of Stems Completed With Targets in Experiment 2 Under Different Experimenter Instructions and/or Subject Strategies

\begin{tabular}{|c|c|c|c|c|c|c|c|c|c|c|c|}
\hline \multirow[b]{2}{*}{ Group } & \multirow[b]{2}{*}{$n$} & \multicolumn{2}{|c|}{ New Cue } & \multicolumn{2}{|c|}{ Synonym } & \multicolumn{2}{|c|}{ Same } & \multicolumn{2}{|c|}{ Low LOE } & \multicolumn{2}{|c|}{ High LOE } \\
\hline & & $M$ & $S E M$ & $M$ & $\overline{S E M}$ & $M$ & $\overline{S E M}$ & $M$ & $\overline{S E M}$ & $M$ & $S E M$ \\
\hline Explicit & 10 & 13.9 & 5.4 & 46.6 & 5.8 & 58.8 & 4.4 & 45.5 & 6.9 & 72.2 & 4.1 \\
\hline All indirect & 27 & 21.6 & 1.3 & 22.0 & 3.2 & 28.3 & 3.7 & 25.8 & 3.7 & 30.8 & 5.1 \\
\hline Unaware & 5 & 16.1 & 3.2 & 12.2 & 3.2 & 7.8 & 2.2 & 8.9 & 4.2 & 6.7 & 2.7 \\
\hline Barely aware & 5 & 21.1 & 2.9 & 13.3 & 4.3 & 21.1 & 4.1 & 24.4 & 8.2 & 17.8 & 7.5 \\
\hline True implicit & 10 & 18.6 & 2.2 & 12.8 & 2.6 & 14.4 & 3.1 & 16.7 & 5.0 & 12.2 & 4.2 \\
\hline Indirect recall & 10 & 24.3 & 2.3 & 39.6 & 5.0 & 49.0 & 6.4 & 49.7 & 5.6 & 47.6 & 8.6 \\
\hline
\end{tabular}

Note-Scores for low LOE and high LOE are for the same condition only. Baseline (unstudied) completion rate was $12.9 \%(S E M=4.0 \%)$. See text for an explanation of the groups. 
fewer than 13 of the 27 subjects claimed that they "caught on" at some point during the test and, from then on, deliberately attempted to recall words from the original list. All of these subjects (henceforth called the indirect recall group) spontaneously mentioned that they had noticed the relationship between the test and study phases in response to the first question of the questionnaire (see Table 4). Five subjects were classified as barely aware: They did not spontaneously mention the study list on the first three questions, but, when specifically asked in the fourth question, they said they had noticed that they had written down some study-list words. These 5 subjects all noticed the critical words toward the end of the test and said they continued to respond with the first word that came to mind after this point. Only 5 subjects remained completely unaware of any connection between the test and the study list (the unaware group). Four miscellaneous subjects did not fit clearly into any of these categories, and their data were discarded for the remainder of the analysis. Three subjects from the indirect recall group started using recall too late in the test to make their results meaningful after this point, and their data were also discarded, leaving only 10 subjects in this group.

One important conclusion from the results of the awareness questionnaire is that a substantial proportion of subjects given indirect instructions reported not following these instructions throughout the whole test. Indeed, by the end of the test, the majority were apparently using explicit memory rather than implicit memory to complete the stems. A particularly striking demonstration that instructions did not control behavior came from 3 subjects from the miscellaneous group: These 3 admitted that they caught on to what they thought was the true requirement of the test (i.e., to complete stems with words from the study list) but then they deliberately chose to write down anything but the words they could recall. (All 3 justified this on the basis of wanting to demonstrate their individuality to the experimenter.)

\section{Truly Implicit Memory?}

Given that some subjects reported using deliberate recall while others did not, the existence, or otherwise, of memory for new associations needs to be examined in each of these groups separately. Table 5 and Figure 1 show the pattern of completion rates over the same, synonym, and new-cue conditions for each of the three primary groups identified from the awareness questionnaire (unaware, barely aware, and indirect recall) plus the explicit control group (direct recall). Performance in the indirect recall group is given as the number of critical items produced after catching on, as a proportion of the number of items remaining in each condition. ${ }^{4}$

From Figure 1, it appears that the pattern of performance, and, particularly, whether memory for new pairs occurred, was determined by whether or not the subjects were using explicit memory to complete test stems: The direct recall and indirect recall groups both demonstrated memory for new associations (i.e., higher completion rates in the same condition than in the new-cue condition),

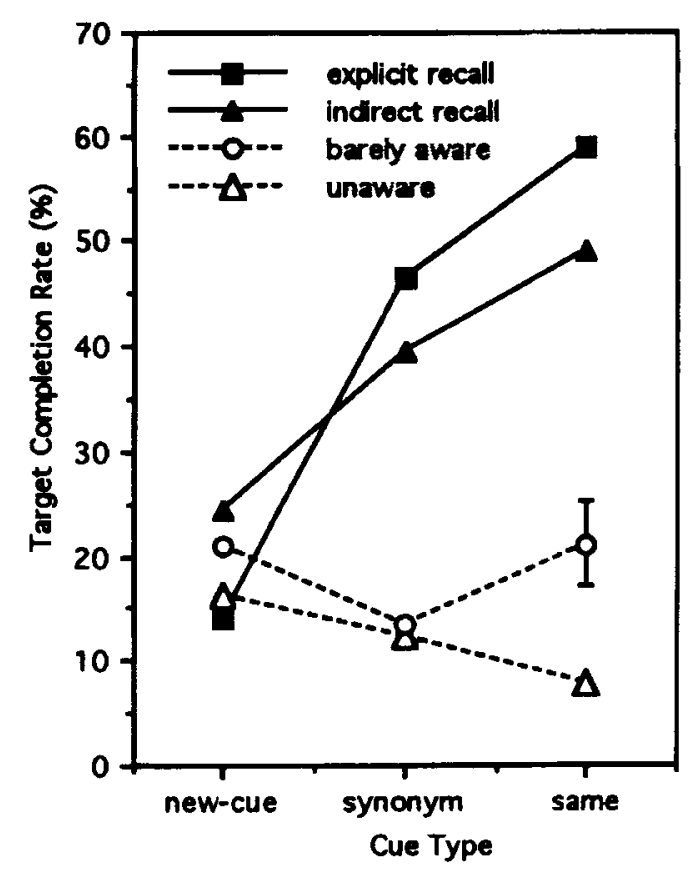

Figure 1. Completion rate with targets in the new-cue, synonym, and same conditions for the explicit recall, indirect recall, barely aware, and unaware groups in Experiment 2. The error bar indicates the average standard error across all conditions.

whereas the unaware and barely aware groups did not. To examine this observation statistically, data from the unaware and barely aware groups were combined to form the true implicit group. This was justified on the basis of the similarity in their completion rates across conditions and was necessary in order to obtain enough subjects (10) in the group to give the statistical analysis any validity.

A two-way ANOVA including test condition (same vs. new-cue) and subject group (direct recall, indirect recall, and true implicit) revealed a significant interaction $\left[F(2,27)=16.37, M S_{\mathrm{e}}=186.2, p<.001\right]$, providing statistical support for the differences in pattern seen in Figure 1 . As we have already shown, control subjects given direct recall instructions exhibited memory for new associations. The indirect recall group similarly demonstrated such an effect $[t(9)=2.69, p<.03$, for same vs. new-cue]. However, no hint of priming for new associations was apparent for the true implicit group $[t(9)=$ $1.7, p>.1]$. The slight difference between the same and new-cue conditions was actually in the wrong direction, and a calculation of a $95 \%$ confidence interval on the mean priming value $(-4.1 \%)$ barely allowed the possibility of any positive priming $(-9.8 \%$ to $+1.4 \%)$. Thus, the results of statistical analysis support the conclusion drawn from an examination of Figure 1-namely, that memory for new associations was evident if and only if the subjects reported employing explicit memory.

These results extend those of Bowers and Schacter (1990), suggesting that it is not mere awareness of the study list that leads to priming for new associations, but rather the subject's deliberate use of recall after becoming aware. 
They demonstrate that "implicit" memory for newly associated pairs can appear to have been found with a stem-completion task, if all indirectly instructed subjects are treated as one group, when, in fact, the effect is due solely to the contribution of the subjects who admit having used explicit memory to recall study-list targets.

\section{Synonym Condition}

As in Experiment 1, no implicit memory for new associations was observed; therefore, the role of semantics in such an effect cannot be investigated. Thus, no analysis of the synonym condition is presented for the true implicit group. For explicit memory, we would expect to find that synonyms of original cues are apt to lead to the subjects' falsely recalling the target, given the common view that explicit memory is based largely on a record of semantic aspects of the original pairing. Congruent with this expectation, Figure 1 demonstrates that both subject groups employing explicit memory showed some confusion between original cues and their synonyms: (false) recall of targets was more common in the synonym condition than in the new-cue baseline for both the direct recall group $[t(9)=8.8, p<.001]$ and the indirect recall group $[t(9)=2.83, p<.025]$.

\section{Level of Elaboration}

The preceding findings indicate that a large proportion of the indirectly instructed subjects were behaving in a manner entirely consistent with using explicit, rather than implicit, memory. First, they openly admitted doing so. Second, they showed memory for new associations, like explicit control subjects, but unlike true implicit subjects. Third, they showed confusion between synonyms, as is commonly found for explicit, but not implicit, memory (e.g., Roediger \& Blaxton, 1987). One final variable on which performance of different subject groups can be compared is the level of semantic elaboration employed at study. As noted earlier, Schacter and Graf (1986a) failed to find an LOE effect under indirect instructions, and they used this to argue that their subjects were not using explicit memory.

Table 5 shows the effect of LOE, for same pairs only, 5 on the memory performance of each group in the present experiment. A two-way ANOVA including LOE (low, high) and subject group (direct recall, indirect recall, and true implicit) revealed a significant interaction $[F(2,27)=$ $\left.6.02, M S_{\mathrm{e}}=248.4, p<.01\right]$; thus, the effect of LOE was evaluated for each group separately. The expected LOE effect was observed for the direct recall group $[t(9)=3.7$, $p<.01]$, but there was no effect of LOE on either the indirect recall group or the true implicit group (both $t \mathrm{~s}<1$ ). This is the first situation we have observed where the performance of the direct recall group was similar to that of the subjects clearly using implicit memory rather than to those clearly using explicit memory.

Does this lack of an LOE effect then indicate that our indirect recall subjects were not, after all, employing explicit memory to complete test stems? We think not, for the following reasons. First, we have found evidence of the use of explicit memory through self-reports, and we have demonstrated that group membership determined on the basis of these self-reports consistently corresponds with performance on other behavioral measures.

Second, a simple difference in the task requirements of directly and indirectly instructed recall subjects may explain the fact that indirectly instructed subjects who reported using explicit memory did not demonstrate an LOE effect. This difference is in the relative difficulty of the task under the two types of instructions and arises from the degree of incentive that the subjects had for using explicit retrieval. Indirectly instructed subjects were told that it was acceptable to complete stems with any word that came to mind and, indeed, were told they should complete every stem. Directly instructed subjects, on the other hand, were given instructions to complete only those stems for which they could recall study-list words-instructions that should have led these subjects to try much harder to recall targets. We can then make the reasonable assumption that LOE effects arise in recall because a higher LOE at study gives the subject more pieces of information linking the cue and the target and, thus, that, given sufficient dedication to the recall task, the subject is more likely to track down the target at test. If this is the case, we might have found no effect of LOE in indirect recall subjects because these subjects were only relatively weakly committed to using recall, given that they knew they must complete many stems not from the study list. On many test trials where a longer search might have led to more accurate recall (i.e., in the high LOE condition), indirectly instructed subjects would often have thought of an alternative completion first and so terminated their search earlier than directly instructed subjects would have.

\section{EXPERIMENT 3}

The results of Experiment 2 are consistent with the view that Graf and Schacter's findings of priming for new associations arose from the use of explicit memory strategies in their indirectly instructed subjects and that, in fact, there is no truly implicit memory for new associations. However, there are a number of methodological differences between Experiment 2 and the earlier studies of Graf and Schacter that might be seen to be responsible for our failure to find implicit memory for new pairs. First, Graf and Schacter allowed only a 3-min study-test delay, whereas we allowed roughly $8 \mathrm{~min}$ in Experiment 2. Second, Graf and Schacter generally used a repair condition (i.e., an old cue word paired with the wrong old stem) as the baseline against which to measure priming, rather than a new-cue condition (i.e., an unstudied cue paired with an old stem). ${ }^{6}$ Third, we allowed each target stem to appear twice on the test list of Experiment 2 (due to the difficulty of selecting unrelated concrete word pairs where a reasonable synonym could be found for the cue). This might have confounded priming due to studyphase exposure with intratest priming.

However, it should be noted that, while any of these differences from Graf and Schacter's standard design 
might have influenced the overall level of priming for new associations, or perhaps the number of subjects catching on and using deliberate recall, it is not at all clear why they would lead to a finding of priming for new associations in one subset of subjects and not others. In addition, the results of Experiment 2 exactly replicated the results of the relevant Graf and Schacter studies when all indirectly instructed subjects were treated as a single group. It was only when this group was divided on the basis of the awareness questionnaire results that we were able to draw the conclusion that no truly implicit memory for new associations was in evidence.

Thus, there are at least two reasons to assume that, while there were experimental differences from earlier studies, these were not responsible for our failure to find implicit memory for new pairs. Despite this, we decided to conduct a third experiment with parameters more similar to those generally employed by Graf and Schacter. The aim of this experiment was to test the generalizability of the results of Experiment 2, to a different set of experimental parameters, to a different set of subjects, and to a different set of target items. Such a test was felt especially important given the small number of subjects found in some subgroups of indirectly instructed subjects and the relatively few items per condition that can be used in a stem-completion paradigm.

In Experiment 3, the study-test delay was reduced to $3 \mathrm{~min}$. Also, a re-pair, rather than a new-cue, condition was used as the baseline against which to measure priming for pairs, and a given target stem appeared as same, re-pair, and unstudied across three different versions of the test list, thus ensuring that each stem was tested only once for each subject. Finally, the synonym condition used in Experiments 1 and 2 and the LOE manipulation of Experiment 2 were dropped, to allow for easier selection of a new set of items and to give the most power in a simple test of the existence of implicit memory for newly associated pairs. The new items were chosen to minimize spontaneous target completion in the unstudied condition; this was done in order to allow the best chance of finding single-word priming (i.e., re-pairs $>$ unstudied) in all subgroups of subjects and was achieved by choosing target words that, while having many easy completions of the 3-letter stem, had at least one more obvious completion that was of higher frequency than the target.

\section{Method}

\section{Subjects}

In total, $39 \mathrm{ANU}$ undergraduates participated in return for course credit, 31 of whom were given indirect memory instructions and 8 of whom were given direct recall instructions.

\section{Design}

Test condition (same, re-pair, or unstudied) was manipulated within subjects, and test instruction (direct or indirect) was manipulated between subjects. The use of an awareness questionnaire allowed subjects given indirect instructions to be further classified as unaware, barely aware, or indirect recall subjects.

\section{Materials}

There were 42 critical word pairs. Members of each pair were semantically unrelated and had no common association with each other. All cue and target words were relatively concrete, as judged by the experimenter (given the constraints of choosing the words described below, it was impossible to ensure that all had listed concreteness ratings). Mean word length was 6.2 letters for cues and 6.7 letters for targets; no target had fewer than 5 letters. Cue words had an average word frequency of 105 occurrences per million, according to the Kučera and Francis (1967) counts. Target words were somewhat less common, with an average frequency of 22 counts per million. The 3 -letter stem of each target word was unique in the list and had at least 10 easy completions. In addition, each stem had at least one completion of substantially higher frequency than the target. This was done in order to achieve a low target-completion rate in the absence of priming for these targets, with the intention of making the design maximally sensitive to any small effects of study-phase exposure to targets.

The 42 pairs were divided into three groups of 14 , corresponding to the same, re-pair, and unstudied conditions. The 28 pairs to be presented at study (same and re-pair conditions) were embedded in sentences, with the to-be-remembered pair underlined. Sentences generally formed meaningful links between the two words but varied somewhat in the degree to which they made sense. Three additional (nontested) sentences were made completely nonsensical, to make the rating task performed by the subjects (see below) appear valid.

In the test list, all 42 pairs appeared, with the stem of each target appearing adjacent to, variously (1) its original partner from the study list (same condition), (2) a different partner from within the same group of 14, which had appeared at study (re-pair condition), or (3) its partner, when both cue and target had not appeared at study (unstudied condition). An additional 30 distractor cue-stem pairs were included, the properties of which were similar to those of the critical pairs, giving 72 items on the test list in total. All test items were presented on a single page, in two columns numbered down the page. The first 10 items were distractors; the rest of the distractors were dispersed throughout the remaining trials.

In order to avoid confounding differences in completion rates between the same, re-pair, and unstudied conditions with item-specific effects, the groups of 14 items were cycled through the three conditions of interest across three versions of the study/test lists. That is, a particular group appeared as same in the first version, re-pair in the second version, and unstudied in the third, whereas a second group appeared as re-pair in the first version, unstudied in the second, and so on. Each subject saw only one version, and data were collapsed across versions.

\section{Procedure}

The subjects were led to expect that the experiment would last for $1 \mathrm{~h}$, although, in fact, it took less than 30 min including debriefing. They were told they would learn a list of pairs of words and would be asked to recall these following a number of distractor tasks. During the study phase, sentences were presented (self-paced) on a Macintosh computer using HyperCard. The subjects were required to read each sentence aloud, to note the two underlined words (as a pair) for the later memory test, and to rate the sentence for the degree to which it sensibly linked these words together (in order to ensure semantic processing of the pair). Three practice trials were given before the experimental study phase. Following this phase, a new city-names distractor task was given, where the subjects were allowed 3 min to think of as many city or town names as possible starting with each letter of the alphabet.

The test phase then followed. The directly instructed subjects were informed that this was the memory test and were told to, initially, work their way through the test list in order (they were allowed to go back over the list after attempting all items once, although this elicited very few additional completions). For each test 
item, these subjects were instructed to examine the first word of each pair and then to complete, where possible, the adjacent stem with the paired word from the study list. The subjects were warned that many of the items were new, and, thus, they should not expect to be able to complete all stems with study-list items.

For the indirectly instructed subjects, the test phase was presented as a second distractor task. These subjects were told to work their way through the test list in order, reading aloud the first word of each pair, then completing the adjacent stem with the first word that came to mind. The subjects were instructed to spend no more than a few seconds on any one item and to move on if they could not think of a completion for the stem; they were not allowed to return to missed items. Following completion of the test phase, indirectly instructed subjects were administered the awareness questionnaire, as described in Experiment 2.

\section{Results and Discussion}

\section{Explicit Recall}

Table 6 presents the percentage of stems completed with target items in the same, re-pair, and unstudied conditions for all subjects. For the direct recall subjects, a oneway ANOVA indicated significant differences among the completion rates for the three conditions $[F(2,14)=12.13$, $\left.M S_{\mathrm{e}}=109.3, p<.005\right]$. Follow-up $t$ tests indicated that performance in the same condition was significantly better than in either the re-pair $[t(7)=2.7, p<.05]$ or the unstudied $[t(7)=5.0, p<.005]$ condition, with the re-pair condition showing a marginal advantage over unstudied pairs $[t(7)=2.0, p=.086]$. The substantial advantage of the same condition $(25.9 \%)$ over the re-pair condition $(8.0 \%)$ clearly demonstrates explicit memory for the pairs. It should be noted, however, that the overall explicit memory performance was poor (although by no means at floor level), a point that will be returned to shortly.

\section{Awareness Questionnaire}

The results of the awareness questionnaire indicated that, in contrast to Experiment 2, only a small number of subjects given indirect instructions admitted attempting to use deliberate recall ( 3 out of 31 ). Of the remaining indirectly instructed subjects, 20 were classified as unaware and 8 were classified as barely aware of the relationship between study and test, using the criteria described in Experiment 2.

\section{Stem Completion}

With the present design, priming for single words is revealed where the completion rate is higher in the repair condition than in the unstudied condition, and priming for the pairings learned at study is revealed where the

\section{Table 6}

Percentage of Stems Completed With Targets in Experiment 3

\begin{tabular}{|c|c|c|c|c|c|c|c|}
\hline \multirow[b]{2}{*}{ Group } & \multirow[b]{2}{*}{$n$} & \multicolumn{2}{|c|}{ Unstudied } & \multicolumn{2}{|c|}{ Re-Pair } & \multicolumn{2}{|c|}{ Same } \\
\hline & & $M$ & SEM & $M$ & SEM & $M$ & $S E M$ \\
\hline Explicit & 8 & 0.9 & 0.9 & 8,0 & 3.4 & 25.9 & 5.6 \\
\hline Unaware & 20 & 6.4 & 1.5 & 13.9 & 2.1 & 17.5 & 3.3 \\
\hline Barely aware & 8 & 9.8 & 1.9 & 8.9 & 2.6 & 9.8 & 3.8 \\
\hline True implicit & 28 & 7.4 & 1.2 & 12.5 & 1.7 & 15.3 & 2.6 \\
\hline Indirect recall & 3 & 2.4 & 2.4 & 9.5 & 2.4 & 20.2 & 9.8 \\
\hline
\end{tabular}

completion rate is higher in the same condition than in the re-pair condition. Of the indirectly instructed subjects (see Table 6), the 3 who reported using explicit recall showed a pattern consistent with memory for pairs, although no statistical analysis of this pattern was undertaken given the very small number of subjects. For the remaining 28 subjects who apparently employed only implicit memory (i.e., the unaware and barely aware subjects combined), a one-way ANOVA ${ }^{7}$ revealed a significant overall effect of test condition $[F(2,54)=4.32$, $\left.M S_{\mathrm{e}}=104.3, p<.02\right]$. This did not reflect any evidence of implicit memory for new associations; completion in the same condition was only slightly, and far from significantly, above that in the re-pair condition $[t(27)=1.1$, $p>.2]$. Instead, it simply reflected the required priming for individual words, with completion for re-pairs being significantly greater than completion with unstudied cues $[t(27)=2.17, p<.05]$.

So, again, we seem to have failed to find implicit memory for new associations despite clear evidence of explicit memory for such pairs. However, before we can have full confidence in this result, there are two potential problems with the data that need to be resolved. First, it might be argued that the failure to find implicit memory for new pairs was due to a floor effect: As with explicit memory, it can be seen that overall completion rates under indirect instructions were low in comparison with those obtained in Experiment 2 and those generally obtained by Graf and Schacter. However, given that performance was significantly better in both the same and re-pair conditions than when pairs were unstudied, it seems reasonable to conclude that performance was sufficiently above floor level for any differences between the same and repair conditions to emerge.

A second potential problem with the conclusion that same performance equals re-pair performance is that, for the 28 true implicit subjects, the variability of scores for same pairs is substantially larger than for re-pairs (see Table 6). This raises the possibility that memory for new associations is present in subjects using implicit memory, but only in some subjects, leading to a slightly higher mean completion rate and, at the same time, a greater spread of scores in the same condition. (It might also suggest that the lack of a significant same-pair advantage could be due to a lack of power arising through excess error variation in one condition.)

However, a check of the raw data for each subject revealed that, in fact, the greater variability in same scores was due entirely to 1 subject who completed $50 \%$ of items in this condition with targets (compared with a mean of $13.2 \%$ for the remaining subjects). Removal of this outlying subject's data reduced the variability of the same condition to that of the re-pair condition and also had the effect of showing even more clearly that, for 27 of the 28 subjects, same and re-pair completion rates were equal to each other (13.2\% same, $12.2 \%$ re-pair) and were above unstudied levels $(7.7 \%)$.

One final point to be made from the data shown in Table 6 regards the relative performance of the unaware 
and barely aware subjects taken separately, rather than treated as one "true implicit" group. While it is apparent that neither group demonstrated any evidence of implicit memory for pairs, it should be noted that only the barely aware group demonstrated priming for individual words above overall baseline level: For the 8 unaware subjects, performance was equally low in each of the same, re-pair, and unstudied conditions. A likely explanation of this pattern is one raised by Bowers and Schacter (1990) for their similar findings in unaware subjects--namely, that whether or not a subject becomes aware that some stems can be completed with study targets is determined simply by how many targets they happen to think of by chance. Thus, a reasonable interpretation of the data would be that there is no difference in the completion strategies employed by unaware and barely aware subjects; rather, it is simply that subjects who happen to think of target completions at a rate above the (low) unstudied baseline level are more likely to notice the origin of these completions.

\section{Comparison With Experiment 2}

The major conclusion drawn from Experiment 3namely, that there is no implicit memory for new associations - is in agreement with that drawn from Experiment 2. Given that Experiment 3 used a different set of items and a different way of measuring baseline performance, and also obtained both priming of single words (i.e., re-pair > unstudied) and a good-sized sample of 28 subjects who were apparently truly using implicit memory, this experiment has provided a valuable replication of the earlier result.

There are two obvious ways in which the results of Experiment 3 differ from those obtained earlier, for which some explanation needs to be given. First, while roughly the same proportion of indirectly instructed subjects became aware of a study-test relationship in the two experiments, far fewer of these subjects then went on to use explicit memory in Experiment 3: 13 of $27(48 \%)$ in Experiment 2, but only 3 of $31(10 \%)$ in Experiment 3 . Second, substantially lower target-completion rates were observed with explicit memory: $58.8 \%$ for the same-cue condition in Experiment 2, and 25.9\% in Experiment 3. It is likely that these two differences are related. It would seem that the choice, in Experiment 3, of new stems as ones that were relatively less likely to be completed with the target word without earlier exposure $(12.9 \%$ unstudied completion rate in Experiment 2 vs. $7.7 \%$ in Experiment 3 ) did, as desired, have the effect of allowing an advantage of the re-pair condition to emerge. However, it also appears to have made the recall task more difficult.

The fact that recall was more difficult in Experiment 3 can explain why fewer subjects given indirect instructions employed explicit memory strategies: It was more difficult for them to do so. In other words, the proportion of indirectly instructed subjects who utilize explicit memory may depend simply on the ease with which those subjects who become "aware" find they can recall studylist items. This interpretation has implications for earlier findings of priming for new pairs in stem completion: Although we can have no direct knowledge of the proportion of Graf and Schacter's indirectly instructed subjects who chose to employ explicit memory, we can note that their choice of items generally produced relatively high levels of direct explicit recall (commonly around $60 \%$ accuracy in the same condition). This level is similar to that found in our Experiment 2 and suggests that any indirectly instructed subjects who considered using explicit memory would have found it relatively easy to do so.

\section{GENERAL DISCUSSION}

The three experiments reported here found no evidence of truly implicit memory for new associations following a study phase that semantically related the cue and target, with either lexical decision or stem-completion measures. The key findings supporting this conclusion were as follows. First, there was no priming for new associations in lexical decision when the possibility of explicit prediction of the target was removed by presenting it simultaneously with the cue (Experiment 1). Second, the only priming for new associations in stem completion occurred in those subjects who reported deliberately recalling from the study list when given a posttest awareness questionnaire (Experiments 2 and 3 ). Third, indirectly instructed subjects who became aware of a study-test relationship appeared more likely to go on to use deliberate retrieval where it was relatively easy to do so (Experiment 2 vs. Experiment 3).

Our findings suggest that previous observations of priming for new associations (i.e., the studies of Graf \& Schacter, 1985, 1987; Schacter \& Graf, 1986a, 1986b, 1989; and McKoon \& Ratcliff 1979, 1986) arose from explicit contamination of the test measures and, thus, do not provide a true reflection of the properties of implicit memory. Such a conclusion is consistent with a substantial body of previous literature, including, in particular, the results of Dagenbach et al. (1990) and Durgunoğlu and Neely (1987) in lexical decision, and Bowers and Schacter (1990) and Shimamura and Squire (1989) in stem completion. In apparent contrast, however, are several findings described by Graf and Schacter, for which some explanation needs to be provided.

Schacter and Graf (1986a) report that target-completion rates were no higher at the end of the test list than at the beginning. This may, indeed, be valid evidence that their stem-completion priming is implicit, but it could equally well be interpreted as indicating that some subjects were suspicious of the nature of the test (and were attempting to use deliberate recall) right from the beginning. This seems not unlikely when the test list was presented only 3 min after the end of the study phase and when deliberate retrieval was relatively easy.

Graf and Schacter's other arguments for genuinely implicit memory for new associations are based on a variety of dissociations between performance on the indirectly instructed stem-completion task and that on a 
direct recall control task (Graf \& Schacter, 1987; Schacter \& Graf, 1986a, 1989). We believe the interpretation of this dissociation evidence might be less obvious than it first appears, because factors other than the variable of interest might have differed between the two tasks. Graf and Schacter's studies do avoid many unwanted sources of potential dissociation by satisfying what Schacter et al. (1989) call the retrieval intentionality criterion. That is, the Graf and Schacter studies maintained all but one aspect of each experiment the same across the indirect stem-completion task and the direct stem-cued recall task (e.g., the study task, the study list, the materials shown to the subject at test); the only difference was in the nature of the test instructions. Thus, they argue that any difference in performance under direct and indirect instructions demonstrates that the stem-cued recall task tapped explicit memory, whereas the stem-completion task tapped implicit memory.

We would argue, however, that different test instructions may induce more complex behaviors than simply pure implicit or explicit retrieval. For example, we found in Experiment 2 that subjects given indirect instructions who reported using deliberate recall showed no advantage from an increased LOE at study, despite replication of the standard LOE effect in subjects given direct recall instructions. We have interpreted this failure as arising from differences in the degree of commitment to using recall between indirectly and directly instructed subjects rather than as evidence that the indirectly instructed group never use recall at all. In keeping with this interpretation, Jacoby, Toth, and Yonelinas (1993) reported no LOP effect in the inclusion task of Jacoby (1991). In this task, subjects are instructed to complete stems with studied words if possible, but to choose any word otherwise. The inclusion task clearly involves explicit memory, and yet performance on it is dissociated from that on stem-cued recall because it fails to show an LOP effect.

Our findings, and those of Jacoby et al. (1993), make the general point that dissociations between direct and indirect task performance should be considered as evidence that the indirect task is not tapping the same memory form in the same way as is the direct task, but not as evidence that it is therefore tapping purely implicit memory. This point holds even when the study phase and test materials are held constant across the two tests; a difference in task instructions may induce differences in subject behavior other than just the implicit or explicit nature of their retrieval. Thus, we argue that satisfying what Schacter et al. (1989) call the retrieval intentionality criterion does not, in fact, ensure that the intentionality of retrieval can be determined unequivocally.

Given these doubts about the interpretation of Graf and Schacter's dissociations, the weight of the evidence strongly favors the view that implicit memory for new associations does not exist, in either amnesics or normals. One qualification of this conclusion must be mentioned, however. The previous studies emphasized in this article, and our own experiments, encompass situations in which a semantic study phase has been employed. Particularly, study has usually involved forming a novel association between the cue and target by considering the degree of intrinsic semantic relationship between these items (e.g., a judgment of how well they go together) or attempting to construct some plausible semantic relationship (e.g., putting them in a sentence). Recent work by Reingold and Goshen-Gottstein (1996) has investigated the issue of explicit contamination of "implicit" memory for new associations using Jacoby's (1991) process dissociation procedure. Their results agree with those reported here for semantically elaborated study: All priming under these conditions was attributable to the explicit (recollective) component of performance, whereas none was attributable to the implicit (automatic) component. With a study phase simply requiring subjects to copy the pairs, however, Reingold and Goshen-Gottstein did find priming for new associations, which was attributable to genuinely implicit retrieval (also see Micco \& Masson, 1991). Thus, it might be that implicit memory for new associations can exist under some circumstances, if not under those of semantic study investigated in the present experiments and the bulk of the previous literature.

The present findings have general implications for the validity of certain tasks commonly used to measure implicit memory and, particularly, for the interpretation of old data obtained with these tasks. Specifically, we believe it is inappropriate to treat all subjects given indirect instructions in stem-completion (or fragment-completion) tasks as necessarily a single group: Our results have indicated that such subjects can report using a variety of strategies and show behavioral patterns that vary consistently with their self-reports. Our findings of explicit memory use by indirectly instructed subjects add weight to previous claims that indirect tests are, in principle, open to influence from explicit knowledge (e.g., Jacoby, 1991; Johnson \& Hasher, 1987; Richardson-Klavehn \& Bjork, 1988; Schacter, 1985). In the absence of hard evidence, these claims have sometimes been overlooked, even relatively recently (e.g., Challis \& Brodbeck, 1992; Micco \& Masson, 1991; Roediger \& McDermott, 1993; Smith, 1991). We hope the present results will help to convince researchers that the problem of explicit contamination can be a real and serious one: As has been shown to be the case with priming for new associations, the reevaluation of old data with more careful methods can prove illuminating.

A number of more appropriate ways of examining implicit memory are now available. For standard studyphase-test-phase designs employing memory-like tests (e.g., recall, stem-completion, Jacoby's inclusion task, etc.), Roediger and McDermott (1993) provide a thorough review of current techniques. This will not be repeated here. We would note, however, that the Roediger and McDermott review includes little discussion of the likely worth of RT paradigms, in which tasks, such as lexical decision, oral reading, visual search, and so on, are used to assess priming by comparing RTs to first and second presentations of a repeated target. In our view, these tasks are far less open to explicit contamination 
than are (uncontrolled) stem-completion or fragmentcompletion measures, as long as the subject has no way of using any explicit recollection to predict the upcoming target. RT tasks also have the advantage that the number of items that can be presented to a single subject is much larger than in tasks that require separate study and test phases, giving the option of obtaining more reliable data over a larger number of conditions.

The theoretical issue addressed by our data concerns the role of preexisting representations in producing implicit memory and, in particular, whether implicit memory relies on modification of preexisting knowledge or the acquisition of novel traces of particular study episodes. The answer to this question would appear fundamental to any theory of implicit memory (Schacter, 1987), but no conclusive answer has to date been provided.

Our reinterpretation of the data on priming for new associations in normals favors a modification of preexisting representations view. This reinterpretation makes results in normals consistent with the amnesic data: Priming is observed for familiar words or pairings in normals and severely amnesic patients; conversely, implicit memory is not found for newly associated word pairs, which have no well-established representations, in either normals or amnesics.

Other ways of addressing the nature of the representations underlying implicit memory, however, do not support the view that priming arises from modification of old knowledge. Priming has been found to be sensitive to the overlap between study and test in physical features, such as presentation modality and case (e.g., Jacoby, 1983; Kirsner \& Smith, 1974; Roediger \& Blaxton, 1987; Standen, 1988), which suggests that implicit memory relies on novel traces of individual context-specific episodes rather than on modification of abstract context-free units. A priori, study-test mismatch effects seem to conflict with our evidence that priming relies on access to preexisting representations, and, at present, we are not in a position to provide a solution of this conflict (although see Carr \& Brown, 1990, and Coltheart, 1989, for some relevant ideas).

Thus, while the present results have clarified a contradictory literature regarding the existence of truly implicit memory for new associations, they have made the theoretical interpretation of implicit memory, if anything, less clear. Our data do show, however, that preexisting representations will have an essential role to play somewhere in an eventual explanation of implicit memory phenomena.

\section{REFERENCES}

Bowers, J. S. (1994). Does implicit memory extend to legal and illegal nonwords? Journal of Experimental Psychologv: Learning, Memory, \& Cognition, 20, 534-549.

Bowers, J. S., \& Schacter, D. L. (1990). Implicit memory and test awareness. Journal of Experimental Psychology: Learning, Memory, \& Cognition, 16, 404-416.

Burt, J. S., \& Humphreys, M. S. (1993). Delayed priming of the pronunciation of inconsistent words and pseudowords. Journal of Memory \& Langlaage, 32, 743-765.

CARR, T. H.. \& BRoWn, J. S. (1990). Perceptual abstraction and inter- activity in repeated oral reading: Where do things stand? Journal of Experimental Psychology: Leaming, Memory, \& Cognition, 16, 731-738.

Carroll, M., \& Kirsner, K. (1982). Context and repetition effects in lexical decision and recognition memory. Journal of Verbal Learning \& Verbal Behavior, 21, 55-69.

Cermak, L. S. (1984). The episodic/semantic distinction in amnesia. In L. R. Squire \& N. Butters (Eds.), The neuropsychology of memory (pp. 55-62). New York: Guilford.

Challis, B. H., \& BRodbecK, D. R. (1992). Level of processing affects priming in word fragment completion. Journal of Experimental Psychology: Learning, Memory, \& Cognition, 18, 595-607.

Coltheart, M. (1989). Implicit memory and the functional architecture of cognition. In S. Lewandowsky, J. C. Dunn, \& K. Kirsner (Eds.), Implicit memory: Theoretical issues (pp. 285-297). Hillsdale, $\mathrm{NJ}$ : Erlbaum.

Dagenbach, D., Horst, S., \& Carr, T. H. (1990). Adding new information to semantic memory: How much learning is enough to produce automatic priming? Journal of Experimental Psychology: Learning, Memory, \& Cognition, 16, 581-591.

Dorfman, J. (1994). Sublexical components in implicit memory for novel words. Journal of Experimental Psychology: Learning, Memory, \& Cognition, 20, 1108-1125.

DurgunoǦlu, A. Y., \& NeEly, J. H. (1987). On obtaining episodic priming in a lexical decision task following paired-associate learning. Journal of Experimental Psychology: Learning, Memory, \& Cognition, 13, 206-222.

Graf, P., \& MANDLER, G. (1984). Activation makes words more accessible, but not necessarily more retrievable. Journal of Verbal Learning \& Verbal Behavior, 23, 553-568.

GRAF, P., \& SCHACTER, D. L. (1985). Implicit and explicit memory for new associations in normal and amnesic subjects. Journal of Experimental Psychology: Learning, Memory, \& Cognition, 11, 501-518.

Graf, P., \& SCHACTER, D. L. (1987). Selective effects of interference on implicit and explicit memory for new associations. Journal of Experimental Psychology: Learning, Memory, \& Cognition, 13, 45-53.

Hintzman, D. L., \& Caulton, D. A. (1995, November). Retrieval dynamics of recognition memory and lexical decision. Paper presented at the 36th Annual Meeting of the Psychonomic Society, Los Angeles.

JACOBY, L. L. (1983). Remembering the data: Analyzing interactive processes in reading. Journal of Verbal Learning \& Verbal Behavior, 22, 485-508.

JACOBY, L. L. (1991). A process dissociation framework: Separating automatic from intentional uses of memory. Journal of Memory \& Language, 30, 513-541.

JaCoby, L. L., Toth, J. P., \& Yonelinas, A. P. (1993). Separating conscious and unconscious influences of memory: Measuring recollection. Journal of Experimental Psychology: General, 122, 139-154.

JACOBY, L. L., \& WITHERSPOON, D. (1982). Remembering without awareness. Canadian Journal of Psychology, 36, 300-324.

JOHNSON, M. K., \& HASHER, L. (1987). Human learning and memory. Annual Review of Psychology, 38, 631-668.

KiRSNER, K., \& SMITh, M. C. (1974). Modality effects in word identification. Memory \& Cognition, 2, 637-640.

KuČERA, M., \& FRANCIS, W. (1967). Computational analysis of present day American English. Providence, RI: Brown University Press.

MANDLER, G. (1980). Recognizing: The judgment of previous occurrence. Psychological Review, 87, 252-271.

MCKoOn, G., \& RatCliff, R. (1979). Priming in episodic and semantic memory. Journal of Verbal Learning \& Verbal Behavior, 18, 463-480.

McKoon, G., \& RatclifF, R. (1986). Automatic activation of episodic information in a semantic memory task. Journal of Experimental Psychology: Learning, Memory, \& Cognition, 12, 108-115.

MCKoon, G., \& RatClifF, R. (1992). Spreading activation versus compound cue accounts of priming: Mediated priming revisited. Journal of Experimental Psychology: Learning, Memory, \& Cognition, 18, $1155-1172$.

MCNamara, T. P. (1992). Priming \& constraints it places on theories of memory and retrieval. Psychological Review, 99, 650-662.

Micco, A., \& Masson, M. E. J. (1991). Implicit memory for new associations: An interactive process approach. Journal of Experimental Psychologi: Learning, Memory, \& Cognition, 17, 1105-1123. 
MORTON, J. (1969). Interaction of information in word recognition. Psychological Review, 76, 165-178.

MORTON, J. (1979). A functional model for memory. In D. A. Norman (Ed.), Models of human memory (pp. 203-254). New York: Academic Press.

Moscovitch, M. (1982). Multiple dissociations of function in amnesia. In L. S. Cermak (Ed.), Human memory and amnesia (pp. 337-370) Hillsdale, NJ: Eribaum.

Musen, G., \& SQuiRe, L. R. (1993). On the implicit learning of novel associations by amnesic patients and normal subjects. Neuropsychology, 7, 119-135.

NeELY, J. H., \& DuRGunoĞLu, A. Y. (1985). Dissociative episodic and semantic priming effects in episodic recognition and lexical decision tasks. Journal of Memory \& Language, 24, 466-489.

Paivio, A., Yuille, J. C., \& Madigan, S. (1968). Concreteness, imagery and meaningfulness values for 925 nouns. Journal of Experimental Psychology Monographs, 76 (1, Pt. 2).

Reingold, E. M., \& GoshEN-GotTsteIN, Y. (1996). Separating consciously controlled and automatic influences in memory for new associations. Journal of Experimental Psychology: Learning, Memory. \& Cognition, 22, 397-406.

RiCHARDSON-KLAVEHN, A., \& BJoRK, R. A. (1988). Measures of memory. Annual Review of Psychology, 39, 475-543.

Roediger, H. L., III, \& Blaxton, T. A. (1987). Retrieval modes produce dissociations in memory for surface information. In D. S. Gorfein \& R. R. Hoffman (Eds.), Memory and cognitive processes: The Ebbinghaus centennial conference (pp. 349-379). Hillsdale, NJ: Erlbaum.

ROEDIGER, H. L., III, \& MCDERMOTT, K. B. (1993). Implicit memory in normal human subjects. In F. Boller \& J. Grafman (Eds.), Handbook of neuropsychology (Vol. 8, pp. 63-131). Amsterdam: Elsevier.

Salasoo, A., Shiffrin, R. M., \& Feustel, T. C. (1985). Building permanent memory codes: Codification and repetition effects in word identification. Journal of Experimental Psychology: General, 114, 50-77.

SCHACTER, D. L. (1985). Multiple forms of memory in humans and animals. In N. M. Weinberger, J. L. McGaugh, \& G. Lynch (Eds.), Memory systems of the brain: Animal and human cognitive processes (pp. 47-65). New York: Guilford.

SCHACTER, D. L. (1987). Implicit memory: History and current status. Journal of Experimental Psychology: Learning, Memory, \& Cognition, 13, 501-518.

SCHACTER, D. L., BOWERS, J., \& BOOKER, J. (1989). Intention, awareness and implicit memory: The retrieval intentionality criterion. In S. Lewandowsky, J. C. Dunn, \& K. Kirsner (Eds.), Implicit memory: Theoretical issues (pp. 47-65). Hillsdale, NJ: Erlbaum.

SCHACTER, D. L., \& GraF, P. (1986a). Effects of elaborative processing on implicit and explicit memory for new associations. Journal of Experimental Psychology: Learning, Memory, \& Cognition, 12, 432-444.

SCHACTER, D. L., \& GRaF, P. (1986b). Preserved learning in amnesic patients: Perspectives from research on direct priming. Journal of Clinical \& Experimental Neuropsychology, 8, 727-743.

SCHACTER, D. L., \& GRAF, P. (1989). Modality specificity of implicit memory for new associations. Journal of Experimental Psychology: Learning, Memory, \& Cognition, 15, 3-12.

Shimamura, A. P., \& Squire, L. R. (1989). Impaired priming of new associations in amnesia. Journal of Experimental Psychology: Learning, Memory, \& Cognition, 15, 721-728.

SмIтH, M. C. (1991). On the recruitment of semantic information for word fragment completion: Evidence from bilingual priming. Journal of Experimental Psychology: Learning, Memory, \& Cognition, 17, 234-244

Smith, M. C., Macleod, C. M., Bajn, J. D., \& Hoppe, R. B. (1989). Lexical decision as an indirect test of memory: Repetition priming and list-wide encoding as a function of type of encoding. Journal of Experimental Psychology: Learning, Memory, \& Cognition, 15, 1109-1118.

STANDEN, P. (1988). Auditory and visual word recognition. Unpublished doctoral dissertation, University of Western Australia.

Toth, J. P., ReINGOLD, E. M., \& J ACOBY, L. L. (1994). Toward a redefinition of implicit memory: Process dissociations following elaborative processing and self-generation. Journal of Experimental Psychology: Learning, Memory, \& Cognition, 20, 290-303.

WARRINGTON, E. K., \& WEISKRANTZ, L. (1968). New method of testing long-term retention with special reference to amnesic patients. $\mathrm{Na}$ ture, 217, 972-974.

WarRINGTON, E. K., \& WeiskranTZ, L. (1970). Amnesic syndrome: Consolidation or retrieval? Nature, 228, 628-630.

WarRington, E. K., \& Weiskrantz, L. (1974). The effect of prior learning on subsequent retention in amnesic patients. Neuropsychologia, 12, 419-428.

\section{NOTES}

1. Throughout this paper, data from within-subject manipulations did not violate the sphericity assumption of repeated measures ANOVA.

2. It is striking that no evidence of priming for new associations was apparent, despite the fact that the subjects were perfectly aware of the study-test relationship at test. This finding is consistent with the view that explicit memory does not contribute to performance on RT tasks when such recollection cannot be used to predict the response to the upcoming target.

3. The nonparametric Wilcoxon's rank-sum test was used here, since both variances and $n$ s were unequal.

4. The performance of the indirect recall group could not be analyzed before the point at which the subjects caught on, since there were insufficient data: On average, the subjects had caught on by the 17 th item on the test list. However, there was no indication of any priming for new associations before this point (new-cue performance $=21.6 \%$, same $=$ $11.1 \%)$.

5. LOE effects were not examined for the new-cue or synonym conditions because, for these conditions, a target response was incorrect This makes any observed effects of LOE impossible to interpret. Fo example, a null effect of LOE in either of these conditions could arise even if a higher LOE leads to better memory: The subject may be more likely to recollect the original target but also more likely to realize that its stem has appeared with the wrong (nonstudied) cue.

6 . We consider it most unlikely that this particular difference in design is of any real importance: Two previous studies have included both re-pair and new-cue baselines (Graf \& Schacter, 1985; Micco \& Masson, 1991) and have reported no difference between them.

7. Ideally, a two-way ANOVA including test condition and test instruction would be conducted before proceeding to examine indirect subjects separately. This was not done because both sample sizes and variances differed substantially across the indirect and direct groups.

(Manuscript received September 21, 1994; revision accepted for publication January $15,1996$. 